Ĭgdır Üniversitesi Fen Bilimleri Enstitüsü Dergisi, 11(3): 1792-1802, 2021

Journal of the Institute of Science and Technology, 11(3): 1792-1802, 2021

Biyoloji / Biology

ISSN: 2146-0574, eISSN: 2536-4618 DOI: 10.21597/jist.876831

Araştırma Makalesi / Research Article

Geliș tarihi / Received: 08-02-2021

Kabul tarihi / Accepted: 29-03-2021

Atıf İçin: Behçet L, Yapar Y, 2021. Asteraceae, Fabaceae ve Lamiaceae Familyalarına Ait B8 Karesi İçin Yeni Floristik Kayıtlar. Iğdır Üniversitesi Fen Bilimleri Enstitüsü Dergisi, 11(3): 1792-1802.

To Cite: Behçet L, Yapar Y, 2021. New Florositic Records For B8 Square Belonging To Asteraceae, Fabaceae And Lamiaceae Families. Journal of the Institute of Science and Technology, 11(3): 1792-1802.

\title{
Asteraceae, Fabaceae ve Lamiaceae Familyalarına Ait B8 Karesi İçin Yeni Floristik Kayıtlar
}

\section{Lütfi BEHÇET ${ }^{1}$, Yakup YAPAR ${ }^{1 *}$}

ÖZET: Bu çalışma, 2018-2020 yılları arasında Çapakçur vadisinde (Bingöl) gerçekleştirilmiştir. Bu vadide yayılışı belirlenen Asteraceae (Compositae), Fabaceae (Leguminosae) ve Lamiaceae (Labiatae) familyalarına ait 52 taksonun B8 karesindeki yayılışları ilk defa verilmiştir. B8 karesi için yeni kayıt olan bu taksonlardan 9 tanesi endemiktir. Verilen taksonların, 30'u Asteraceae, 9'u Fabaceae, 13'ü Lamiaceae üyesidir. Çalışmada sunulan taksonların fitocoğrafik bölgelere dağılımları şu şekildedir: 19 takson İran-Turan, 5 takson Avrupa-Sibirya, 4 takson Akdeniz ve 24 takson fitocoğrafik bölgesi bilinmeyen veya geniş yayılışladır.

Anahtar Kelimeler: Çapakçur vadisi, yeni kayıt, B8 karesi, Asteraceae, Fabaceae, Lamiaceae

\section{New Florositic Records For B8 Square Belonging To Asteraceae, Fabaceae And Lamiaceae Families}

ABSTRACT: This study was carried out between 2018-2020 in the Çapakçur valley (Bingöl). The distribution of 52 taxa belonging to the families Asteraceae (Compositae), Fabaceae (Leguminosae) and Lamiaceae (Labiatae), which were determined to be distributed in this valley, was given for the first time in the B8 square. 9 of these taxa, which are new records for the B8 square, are endemic. Of the given taxa, 30 are Asteraceae, 9 are Fabaceae and 13 are Lamiaceae members. The distribution of the taxa presented in the study to phytogeographical regions is as follows: 19 taxa are Iran-Turan, 5 taxa are Euro-Siberian, 4 taxa are Mediterranean and 24 taxa are unknown or widespread.

Keywords: Çapakçur valley, new record, B8 square, Asteraceae, Fabaceae, Lamiaceae

${ }^{1}$ Lütfi BEHÇET (Orcid ID: 0000-0001-8334-7816), Yakup YAPAR (Orcid ID: 0000-0002-5298-0085) Bingöl Üniversitesi, Fen-Edebiyat Fakültesi, Biyoloji Bölümü, Bingöl, Türkiye

*Sorumlu Yazar/Corresponding Author: Yakup YAPAR, e-mail: yyapar25@gmail.com 


\section{GíRiş}

Bingöl, bitki çeşitliği bakımından oldukça zengin bir il olmasına rağmen bu zenginlik yeterince bilinmemektedir. Bingöl'deki zenginliğin temelinde ilin coğrafik ve ekolojik özellikleri yer almaktadır. Bingöl, Türkiye'nin en yağışlı bölgesi olan Karadeniz Bölgesi’ndeki bazı illerden daha çok yağış almaktadır. Bunun nedeni kuzeyden gelen ve yağış getiren hava akımları ile güneyden gelen ve sıcak hava akımlarının karşılaştı̆ı̆ bir konumda olmasıdır. Dolayısıyla Bingöl çevre illere göre farklı bir iklimin etkisindedir (Kurt, 2014). Söz konusu iklimsel özelliklerin yanı sıra; yükselti farklılıkları, toprak özellikleri ve topoğrafik yapı da Bingöl florasının zenginliğine katkı sağlamaktadır. Nitekim son yıllarda Bingöl'den yapılan yeni tür ve floristik çalışmalar (Behçet ve ark., 2014; Sinan ve Behçet, 2014; Duran ve ark., 2015; Doğan ve ark., 2015; Behçet ve İlçim, 2015; Yapar ve Behçet, 2018; Behçet ve Yapar, 2020a, 2020b) bu görüşü desteklemektedir.

Asteraceae (Papatyagiller), Fabaceae (Baklagiller) ve Lamiaceae (Ballıbabagiller) familyaları dünya ve Türkiye'de en fazla tür içeren familyalar arasında ilk sıradadırlar (Erik ve Tarıkkahya, 2004; Cheek ve ark., 2020). Bu familyalar çok fazla bireye sahip olmalarının yanında tıbbi, ekonomik ve ekolojik öneme de sahiptirler. Dünyanın birçok yerinde, bu familyaların bazı üyeleri gıda, tıbbi ve yem bitkisi amaçlı olarak kullanılmaktadır (Kaval ve ark., 2014; Kawarty, 2020).

$\mathrm{Bu}$ çalışmada; Çapakçur vadisinde (Bingöl) (Şekil 1.) yayılışını belirlediğimiz Asteraceae, Fabaceae ve Lamiaceae üyelerine ait, B8 karesi için yeni kayıtlar yer almaktadır. Dolayısıyla bu araştırma ile yeniden yazılmakta olan Türkiye florası için veri sağlamanın yanı sıra; yapılacak diğer floristik çalışmalar (monograf, revizyon çalışmaları gibi) için de katkıda bulunulmuş olacaktır.

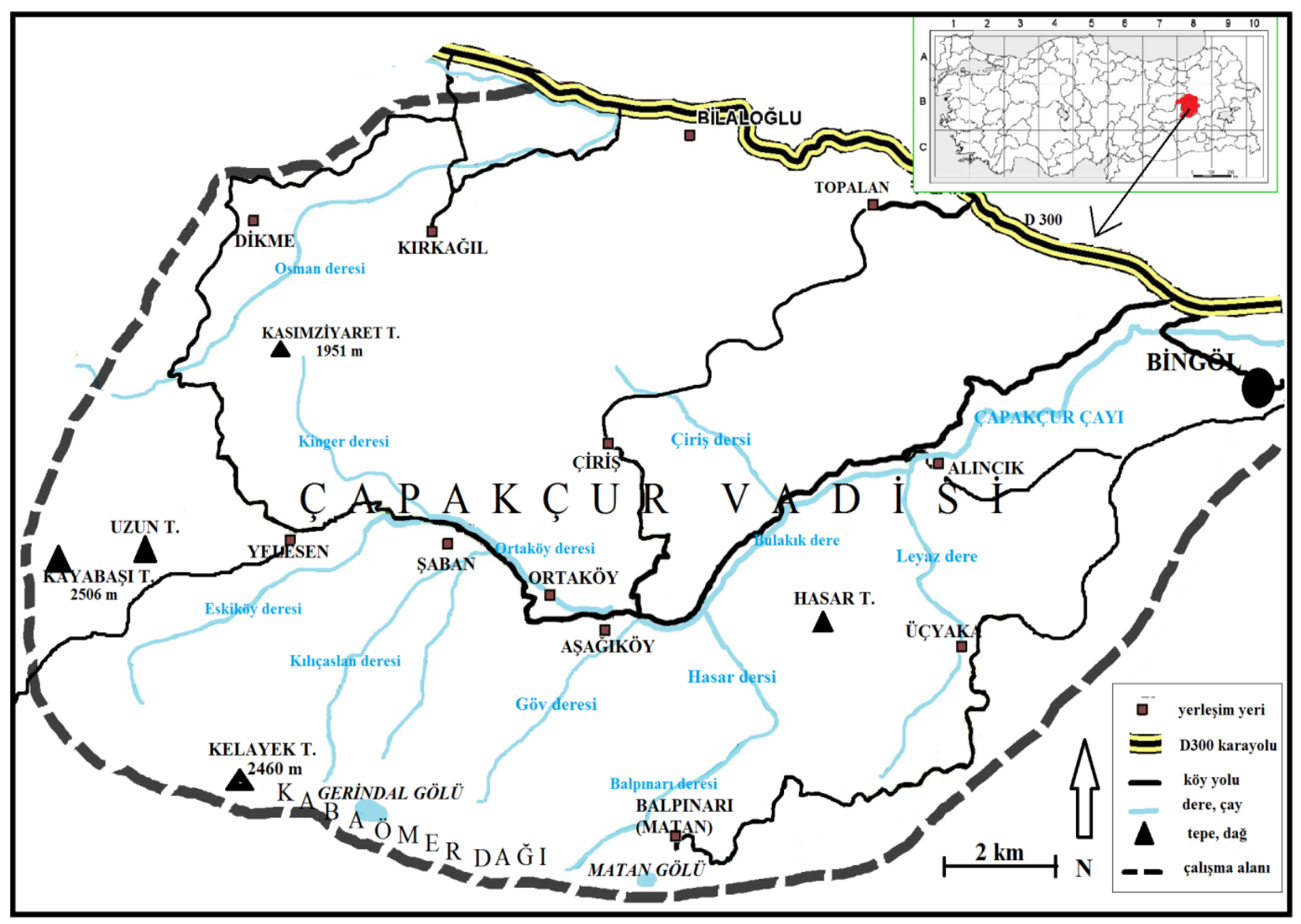

Şekil 1. Çalışma alanı 


\section{MATERYAL VE METOT}

Çalışmada verdiğimiz Asteraceae, Fabaceae ve Lamiaceae üyeleri, 2018-2020 y1lları arasında Bingöl merkez Çapakçur vadisinden tarafımızdan toplanmış olup; B8 karesindeki yayılışları ilk defa belirlenmiştir. Çapakçur vadisi oldukça engebeli ve erozyona maruz kalan bir alandır. Alanın özellikle Aşağıköy-Yelesen köyleri arasındaki sahanın hakim vejetasyon örtüsünü step formasyonları; Alıncık, Üçyaka, Topalan ve Çirişli köyleri çevrelerinde ise orman formasyonu yoğun örtüyü oluşturmuştur. Alandan toplan bitkiler Türkiye florasının ilgili ciltleri (Davis, 1970, 1975, 1982; Davis ve ark., 1988, Güner ve ark., 2000) kullanılarak teşhis edilmiştir. Yeni kayıt listesi; bölge ile ilgili yayınlar (Behçet ve ark., 2014; Behçet ve Yapar, 2020a, Sinan ve Behçet, 2014; Kılıç ve Y1ldırımlı, 2014; K1lıç ve ark., 2017; Yapar ve Behçet, 2018; Y1ldırıml1, 1999, 2005, 2008) taranarak ortaya konmuştur. Belirlenen bitkilerin yazar ve Türkçe isimleri, endemizim durumları, fitocoğrafik bölgeleri ve geçerli güncel bilimsel isimleri, Türkiye Bitkileri Listesi-Damarlı Bitkiler (Güner ve ark., 2012) adlı eser temel alınarak verilmiştir. Endemik bitkilerin tehlike kategorileri ise Türkiye Bitkileri Kırmızı Kitabı referans alınarak yazılmıştır (Ekim ve ark., 2000). Yeni kayıt listesi APG IV (Huston ve ark., 2009) sistemine göre alfabetik sıra ile verilmiştir. Liste oluşturulurken; her bir takson için sırasıyla, taksonun latince adı, Türkçe adı ve lokalite bilgileri düzeninde sunulmuştur. Bitkiler herbaryum materyali haline getirilerek Bingöl Üniversitesi Fen-Edebiyat Fakültesi Biyoloji Bölümü herbaryumunda saklanmaktadır.

\section{BULGULAR VE TARTIŞMA}

B8 karesinden yayılışları belirlenen Asteraceae, Fabaceae ve Lamiaceae üyesi taksonların listesi ASTERACEAE /PAPATYAGILLER

\section{ANTHEMIS L. /PAPATYA}

1. Anthemis arvensis L. /tarla papatyas 1

Bingöl merkez, Kültür mahallesi, bahçe kenarları, 1107 m, 04.08.2020, 3852'53.78"K, 40³0'50.78"D, LY19095; Bingöl merkez, Kültür mahallesi doğusu, bahçe kenarları, $1072 \mathrm{~m}$, 17.09.2020, 3853'8.29"K, 40³1'32.17"D, LY19164, Avrupa-Sibirya Elementi.

2. Anthemis cretica L. subsp. umbilicata (Boiss. \& Huet.) Grierson /babunç

Üçyaka-Balpınarı köyleri arası, 2. km, orman açıkları, 1650-1700 m, 23.06.2019, LY16881; Üçyaka-Balpınarı köyleri arası, 3-4. km, vadi içi, nemli alan, 1800 m, 23.06.2019, LY16934.

2. ARCTIUM L. /LÖȘLEK

3. Arctium platylepis (Boiss. \& Bal.) Sosn. ex Grossh. /baldikeni

Yelesen köyü güneyi, çayır alanlar, 2058 m, 26.07.2018, LY16101, Avrupa-Sibirya elementi.

4. Arctium tomentosum Mill. /hanımyamas1

Bingöl karşıyaka mahallesinden Eski çarşıya giden yol, Çapakçur çayı çevresi, dere kenarı, 1127 m, 20.09.2020, 3853'31.89"K, 40²9'27.85"D, LY19207.

\section{CENTAUREA L. /PEYGAMBERÇİÇEI}

5. Centaurea aggregata Fisch. \& C.A.Mey. ex DC. subsp. albida (K.Koch) Bornm. /akküme

Alıncık köyü güney-güney batısı, step, 1430 m, 15.07.2018, LY15855; Üçyaka-Balpınarı köyleri aras1, 2. km, orman açıkları, 1650-1700 m, 23.06.2019, LY16905; Ortaköy güneyi, step alanlar, 1700 m, 31.07.2019, LY17870, Endemik.

4. CIRSIUM Mill. /KÖYGÖÇÜREN

6. Cirsium pubigerum (Desf.) DC. var. coniforme Petr. /dere kangalı

Şaban köyü yaylasına 2 km kala, dere kenarları, 1914 m, 19.07.2018, LY15969; Ortaköy kuzeyi, nemli alanlar, $1554 \mathrm{~m}, 14.07 .2020$, LY18919.

7. Cirsium pubigerum (Desf.) DC. var. spinosum Petr. /dere kangalı 
Yelesen köyü batısı, yayla yolu 4.km, yolun sağındaki çayır, dere kenarı, $2050 \mathrm{~m}, 02.07 .2018$, LY15577; Aşağıköy’e 1-2 km kala mezarlık karşısındaki vadi, dere kenarları, 1440 m, 27.07.2019, LY17691; Aşağıköy güneyi vadi, dere kenarı, 1500-1600 m, 24.08.2019, LY17910.

5. COTA J.Gay ex Guss. /BABUÇÇA

8. Cota coelopoda (Boiss.) Boiss. var. bourgaei (Boiss.) U. Özbek \& Vural /çiçekçi papatyası

Bingöl il merkezi Kaleönü mahalesi güneyi, tarla, $1031 \mathrm{~m}, 20.05 .2020,38^{\circ} 53^{\prime} 55.86^{\prime \prime} \mathrm{K}$, 40³3'28.41"D, LY18236; Bingöl il merkezi Devlet hastanesi güneyi, Çapakçur vadisi, çay kenarı, 1081 m, 20.05.2020, 3853'33.73"K, 40³0'57.53"D, LY18329.

9. Cota tinctoria (L.) J. Gaye x Guss. var. pallida (DC.) U. Özbek \& Vural /boyac1 papatyas1

Yelesen köyü batıs1, güneye bakan step yamaçlar, 2350m, 28.06.2019, LY17091.

6. CREPIS L. /KISKI

10. Crepis vesicaria L. subsp. vesicaria/kese k1sk1s1

Şaban köyü kuzeybatıs1, step, 1500-1600 m, 30.05.2018, 3852'9.08"K, 40²1'3.00"D, LY15034; Üçyaka-Balpınarı köyleri arası, 2. km, orman açıkları, 1650-1700 m, 23.06.2019, LY16840, Akdeniz elementi

7. ECHINOPS L. /TOPUZ

11. Echinops transcaucasicus Iljin / kaf topuzu (Şekil 2.)

Ortaköy güneyi, step alanlar, 1700 m, 31.07.2019, LY17887, Iran-Turan elementi.

8. FILAGO L. /KEÇEOTU

12. Filago gallica L. /çatal keçeotu

Ortaköy güneyi, dere kenarları, 1615 m, 31.07.2019, LY17807.

9. HIERACIUM L. /ŞAHINOTU

13. Hieracium asterodermum (Woronow \& Zahn) Üksip /yıldız şahinotu

Aşağıköy’e 1-2 km kala mezarlık karşısındaki vadi, dere kenarları, 1440 m, 27.07.2019, LY17682; Aşağıköy’e 1-2 km kala mezarlık karşısındaki vadi, nemli yamaçlar, 1447m, 25.08.2019, LY17944.

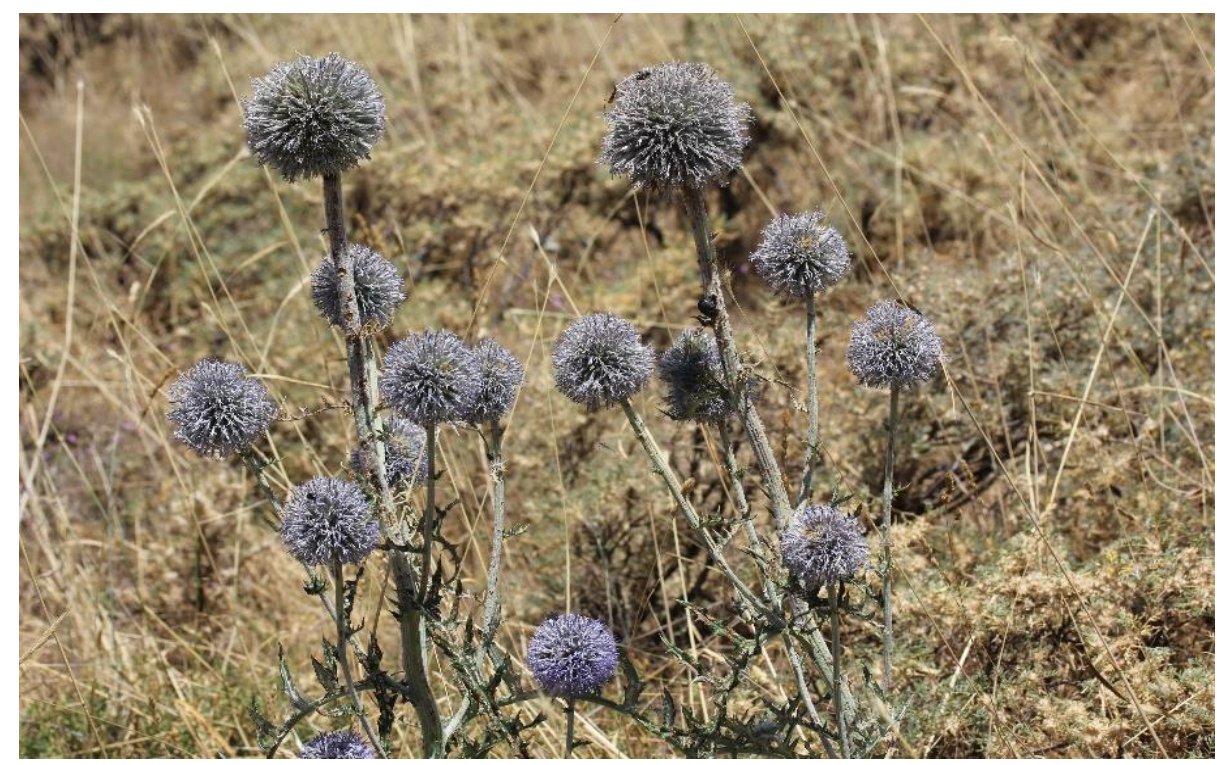

Şekil 2. Echinops transcaucasicus Iljin /kaf topuzu

\section{INULA L. /ANDIZOTU}

14. Inula thapsoides (Willd.) Spreng. subsp. thapsoides /kanatl1 andizotu

Balpınarı eski köy yolu, 1. km, yol kenarı, 1770 m, 29.08.2019, LY18028. 


\section{LEONTODON L. /ASLANDIȘİ}

\section{Leontodon hispidus L. var hispidus /gulikazer}

Aşağıköy-Ortaköy arası yolun güneyi, orman-orman açıkları, $1680 \mathrm{~m}, 17.06 .2020,38^{\circ} 51^{\prime} 3.41^{\prime \prime K}$, 40²1'44.61"D, LY18533; Üçyaka-Balpınarı köyleri arası, 3-4. km, vadi içi, nemli alan, $1800 \mathrm{~m}$, 23.06.2019, LY16940; Üçyaka-Balpınarı köyleri arası, 3-4. km, vadi içi, nemli alan, $1800 \mathrm{~m}$, 23.06.2019, LY16972; Yelesen köyü güneyi, Yelesen yaylası, güneyi, kuzeye bakan step yamaçlar, 2100 m, 18.07.2019, LY17461, Avrupa-Sibirya Elementi.

\section{MATRICARIA L. /ALMANPAPATYASI}

16. Matricaria aurea Sch.Bip /çiçeğe zer

Bingöl il merkezi Selahattin Eyyübi Camii çevresi, 1150 m, 17.06.2020, 3853'37.90"K, 40²9'30.60"D, LY18621.

13. PICRIS L. /ACIŞİRO

17. Picris pauciflora Willd. /kum şirosu

Alıncık köyüne 1 km kala orman açıkları, 1350-1400 m, 06.06.2018, LY15253, Akdeniz elementi. 14. PILOSELLA Vail. /TIRNAKOTU

18. Pilosella x macrotricha (Boiss.) F.W.Schultz \& Sch.Bip. /keçe tırnakotu

Ortaköy kuzeyi, nispeten nemli yerler, 1559 m, 14.07.2020, LY18927.

19. Pilosella $\mathrm{x}$ maschukensis (Litv. \& Zahn) Soják /koru tırnakotu

Alıncık- Aşağıköy arası 3. km, (Çiriş çayı karşısı) yolun solundaki vadi, step, 1495 m, 15.07.2019, LY17435; Topalan-Çirişli köyleri arası, 2. km, orman-orman açılları, 1650 m, 24.06.2020, LY18697.

20. Pilosella piloselloides (Vill.) Soják subsp. magyarica (Peter) S. Braut. \& Greuter /daz tırnakotu

Alıncık köyüne 1 km kala, orman açıkları, 1350-1400 m, 06.06.2018, LY15244; Alıncık-Aşağıköy arası, yolun solundaki vadi, orman- orman açıkları, 1400-1500 m, 07.07.2018, LY15769.

\section{PTILOSTEMON Cass. /BOZLANOTU}

21. Ptilostilon afer (Jacq.)Greuter subsp. eburneus Greuter /has bozlanotu (Şekil 4.)

Şaban köyü girişi, yol kenarı, step, 1577 m, 19.07.2018, LY15952; Şaban köyü girişi, yol kenarı, step, 1577 m, 26.07.2018, LY16111; Ortaköy-Şaban arası yayla yolu, 1. km, step yamaçlar, $1604 \mathrm{~m}$, 31.07.2019, LY17784, Endemik.

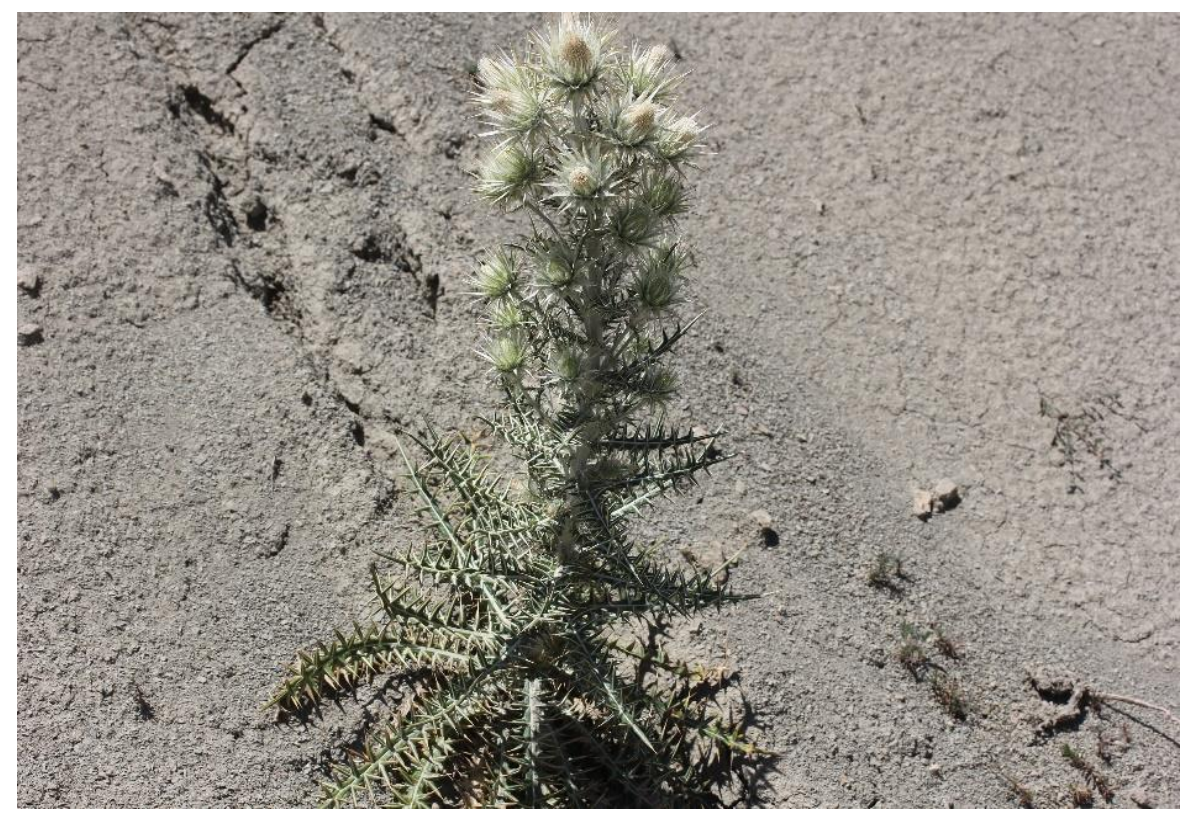

Şekil 3. Ptilostilon afer subsp. eburneus Greuter /has bozlanotu 


\section{SCORZONERA L. /TEKESAKALI}

\section{Scorzonera rigida DC. /sert tekesakalı (Şekil 4.)}

Yelesen köyü batısı, yayla yolu 5-6 km, yol ayrımı, step, 2060 m, 25.07.2018, LY16068, İran Turan elementi.

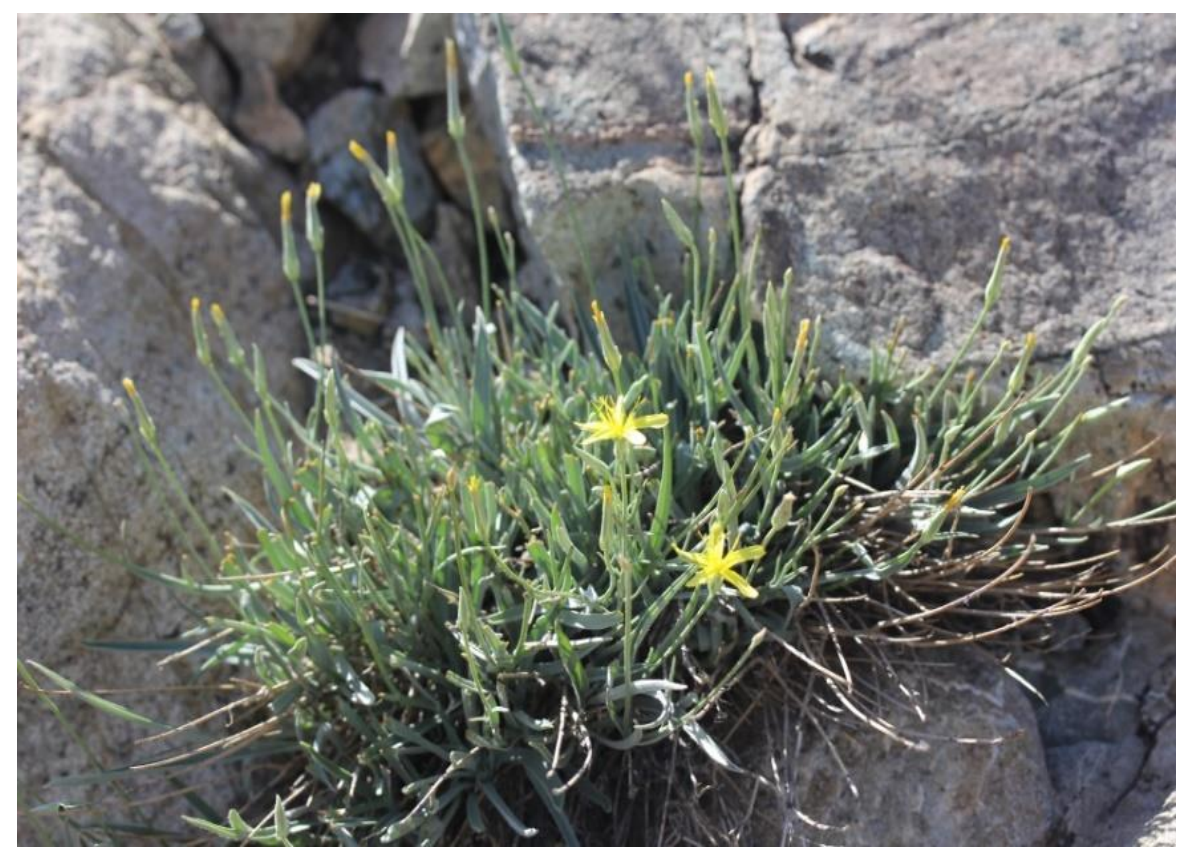

Şekil 4. Scorzonera rigida DC. /sert tekesakalı

\section{SIEBERA J.Gay /FEZAÇIÇEĞİ}

\section{Siebera nana (DC.) Bornm./bodur fezaçiçeği}

Çirişli-Aşağıköy arası yol kenarı, step, 1650 m, 01.07.2020, LY18882; Ortaköy kuzeyi, step, 15201560m, 15.07.2020, LY18975, İran -Turan elementi.

\section{TARAXACUM F.H.Wigg. /KARAHINDIIBA}

\section{Taraxacum davisii Soest/erek hindibası.}

Bingöl il merkezi, eski otogar doğusu, nemli alanlar, $1111 \mathrm{~m}, 14.05 .2020,38^{\circ} 52^{\prime} 53.15^{\prime \prime} \mathrm{K}$, 40³0'42.47"D, LY 18219, Endemik, İran-Turan Elementi.

\section{Taraxacum kurdiciforme G.E.Haglund/bitlis çıtlığ}

Yelesen köyü batısı, yayla yolu 4-5 km, yol kenarı, nemli alanlar, 2150 m, 02.07.2018, LY15667, İran-Turan Elementi.

\section{Taraxacum macrolepium Schischk/kars çıtlığ 1}

Yelesen köyü güneyi, Yelesen yaylası, dere kenarları, 2144 m, 21.07.2019, LY17614

27. Taraxacum revertens G.Hagl. /caşir

Üçyaka-Balpınarı köyleri arası, 3-4. km, vadi içi, nemli alan, 1800 m, 23.06.2019, LY16973, Endemik, İran-Turan Elementi.

\section{Taraxacum stevenii (Spreng.) DC. /gelingöbeği}

Üçyaka- Metan köy yolu, Haziran köyü yol ayrımını geçtikten sonra, çeşme çevresi nemli alan, 1888 m, 08.08.2018, LY16248, İran-Turan Elementi.

18. TRAGOPOGON L. /YEMLIK

\section{Tragopogon pratensis L. subsp. orientalis (L.) Čelak. /salsifin}

Balpınarı köyüne 2-3 km kala, kuzeye bakan yamaçlar, 1910 m, 22.06.2019, LY16773; ÜçyakaBalpınarı köyleri arası, 3.-4. km, vadi içi, nemli alan, 1800 m, 23.06.2019, LY16980; Avrupa-Sibirya elementi. 


\section{Tragopogon pterodes Petrović /çelebi yemlik}

Yelesen köyü batısı, güneye bakan step yamaçlar, 2350m, 28.06.2019, LY17116; Yelesen köyü batıs1, güneye bakan step yamaçlar, 2350m, 28.06.2019, LY17116.

FABACEAE /BAKLAGILLER

\section{ASTRAGALUS L. /GEVEN}

\section{Astragalus xylobasis Freyn \& Bornm. /kemaliye geveni}

Yelesen köyü batıs1, yayla yolu 3.km, step, 1900-2000 m, 23.06.2018, LY15355a; Bingöl il merkezi Devlet hastanesi güneyi, Çapakçur vadisi, çay kenarı, $1081 \mathrm{~m}, 20.05 .2020,38^{\circ} 53^{\prime} 33.73^{\prime \prime K}$, 40³0'57.53"D, LY18341; Ortaköy kuzeyi, step, 1520-1560 m, 15.07.2020, LY18955, İran-Turan elementi.

\section{LATHYRUS L. /MÜRDÜMÜK}

32. Lathyrus hierosolymitanus Boiss. /ova mürdümüğü

Alıncık köyü, köy içi, 1300 m, 23.06.2018, LY15333, Akdeniz elementi.

\section{ONOBRYCHIS Mill. /KORUNGA}

33. Onobrychis stenostachya Freyn subsp. krausei (Sirj.) Hedge/dar korunga

Aşağıköy-Ortaköy arası yolun güneyi, orman-orman açıkları, 1680 m, 16.06.2020, 3851'3.41"K, 40²1'44.61"D, LY18476, Endemik, İran-Turan Elementi.

34. Onobrychis transcaucassica Grossh. /kaf korungas1

Yelesen köyü güneyi, Yelesen yaylası güneyi, kuzeye bakan step yamaçlar, 2100-2200 m, 18.07.2019, LY17529, İran-Turan Elementi.

\section{OXYTROPIS DC. /GAGAGEVENI}

35. Oxytropis aucheri Boiss. /yer gagageveni

Yelesen köyü batısı, yayla yolu 3.km, step, 1900-2000m, 23.06.2018, LY15353; Yelesen köyü batıs1, yayla yolu 5. km, yol ayrımı, step, 2060 m, 02.07.2018, LY15509, İran-Turan Elementi.

36. Oxytropis lupinoides Grossh. /üç gagageveni

Şaban köyü kuzeybatısı, step, 1500-1600 m, 30.05.2018, 3852'9.08"K, 40²1'3.00"D, LY15089, İran-Turan Elementi.

\section{TRIFOLIUM L. /YONCA}

37. Trifolium nigrescens Viv. subsp. nigrescens / yanık üçgül

Yelesen köyü batısı, yayla yolu 4-5 km, yol kenarı, nemli alanlar, 2150 m, 02.07.2018, LY15650.

38. Trifolium repens L. var. macrorrhizum (Boiss.) Boiss. /ak üçgül

Şaban köyü güneyi, Gerindal gölü, göl kenarı, nemli alan, 2374 m, 18.07.2018, LY15944a; Şaban köyü yayla yolu 2. km, nemli alan, 1965 m, 19.07.2018, LY16010.

39. Trifolium roussaeanum Boiss. /has yonca

Bingöl il merkezi Devlet hastanesi güneyi, Çapakçur vadisi, çay kenarı, $1081 \mathrm{~m}, 20.05 .2020$, 38॰53'33.73"K, 40³0'57.53"D, LY18300, Endemik.

\section{LAMIACEAE/BALLIBABAGILER}

\section{MARRUBIUM L. /BOZOTU}

\section{Marrubium cordatum Nebelek /yayla dermesi}

Üçyaka köyünden, Balpınarı köy yolu 1-2. km, orman açıkları, 1650-1700 m, 23.06.2019, LY16929; Üçyaka-Balpınarı köyleri arası, 2. km, orman açıkları, 1650-1700 m, 23.06.2019, LY16929; Üçyaka-Balpınarı köyleri arası, 3-4. km, vadi içi, nemli alan, 1800 m, 23.06.2019, LY16937, İran-Turan Elementi.

\section{Marrubium cuneatum Russel /elkurtaran}


Balpınarı (Metan) köyü girişi, çayır, 1965 m, 22.06.2019, LY16811; Bingöl il merkezi Devlet hastanesi güneyi, Çapakçur vadisi, çay kenarı, $1081 \mathrm{~m}, 20.05 .2020,38^{\circ} 53^{\prime} 33.73$ "K, 40³0'57.53"D, LY18344; Bingöl Karşıyaka mahallesinden Eski çarşıya giden yol, Çapakçur çayı çevresi, step, 1127 m, 20.09.2020, 3853'31.89"K, 40²9'27.85"D, LY19185. İran-Turan Elementi.

24. ORIGANUM L. /MERCANKÖŞK

42. Origanum vulgare L. subsp. viridulum (Martrin-Donos) Nyman /istanbul kekiği

Balpınarı köyü güneyi, Metan Gölü çevresi, nemli alanlar, 1960 m, 29.08.2019, LY18039.

26. PHLOMIS L. /ÇALBA

43. Phlomis bruguieri Desf. /kaba çalba

Topalan köyü doğusu, vadi boyunca, step, $1438 \mathrm{~m}, 17.06 .2020,38^{\circ} 54^{\prime} 32.93^{\prime \prime K}, 40^{\circ} 25^{\prime} 58.43^{\prime \prime} \mathrm{D}$, LY18669, İran-Turan Elementi.

27. SCUTELLARIA L. /KASIDE

44. Scutellaria albida L.subsp. velenovskyi (Rech.f.) Grauter \& Burdet /benekli kaside

Alıncık-Aşağıköy arası, yolun solundaki vadi, orman- orman açıkları, 1400-1500 m, 07.07.2018, LY15772; Topalan-Çirişli köyleri arası, Topalan köyü çıkışı, orman-orman açıkları, $1640 \mathrm{~m}$, 23.06.2020, LY18680.

45. Scutellaria brevibracteata Stapf subsp. brevibracteata/yağlı kaside

Alıncık köyü güney-güney batısı, step, 1430 m, 15.07.2018, LY15867, Endemik, D. Akdeniz elementi

46. Scutellaria orientalis L.subsp. haussknechtii (Boiss.) J.R.Edm. /saçakl1 kaside

Alıncık köyü güney-güney batısı, step, 1430 m, 15.07.2018, LY15877, Endemik, İran-Turan Elementi.

47. Scutellaria orientalis L. subsp. macrostegia (Hausskn. ex Bornem.) J.R.Edm. /takkeli kaside

Aşağıköy’e 1-2 km kala, güneye doğru uzanan vadi, step, 1600-1650 m, 08.07.2019, LY17347; Aşağıköy'e 1-2 km kala mezarlık karşısındaki vadi, step, 1600 m, 28.07.2019, LY17744. Endemik, İranTuran Elementi.

28. STACHYS L. /DELIÇAY

48. Stachys annua subsp. annua var. lycaonica Bhattacharjee/haciosmanotu (Şekil 5.)

Alıncık köyü, köy içi, 1300 m, 23.06.2018, LY15316; Yelesen köyü güneyi, step, 2080 m, 26.07.2018, LY16105; Ortaköy güneyi, 2 km, step yamaçlar, 2110 m, 12.06.2019, LY16550, İran-Turan Elementi.

49. Stachys bithynica Boiss. /ulu deliçay

Yelesen köyü güneyi, Yelesen yayla çevresi, step, 2150 m, 20.07.2019, LY17571; Ortaköy güneyi, step alanlar, 1700 m, 31.07.2019, LY17874, Avrupa-Sibirya elementi.

50. Stachys iberica M.Bieb. subsp. georgica Rech.f., /üç deliçay

Alıncık köyüne $2 \mathrm{~km}$ kala, step yamaçlar, 1430-1450 m, 06.06.2018, 3852'23.22"K, 40²6'53.95"D, LY15199; Şaban köyü yayla yolu 2. km, çayır alanlar, 2071 m, 19.07.2018, LY16048; Yelesen köyü batısı, 3. km, çayır, 2014 m, 29.06.2019, LY17159, İran-Turan Elementi. 


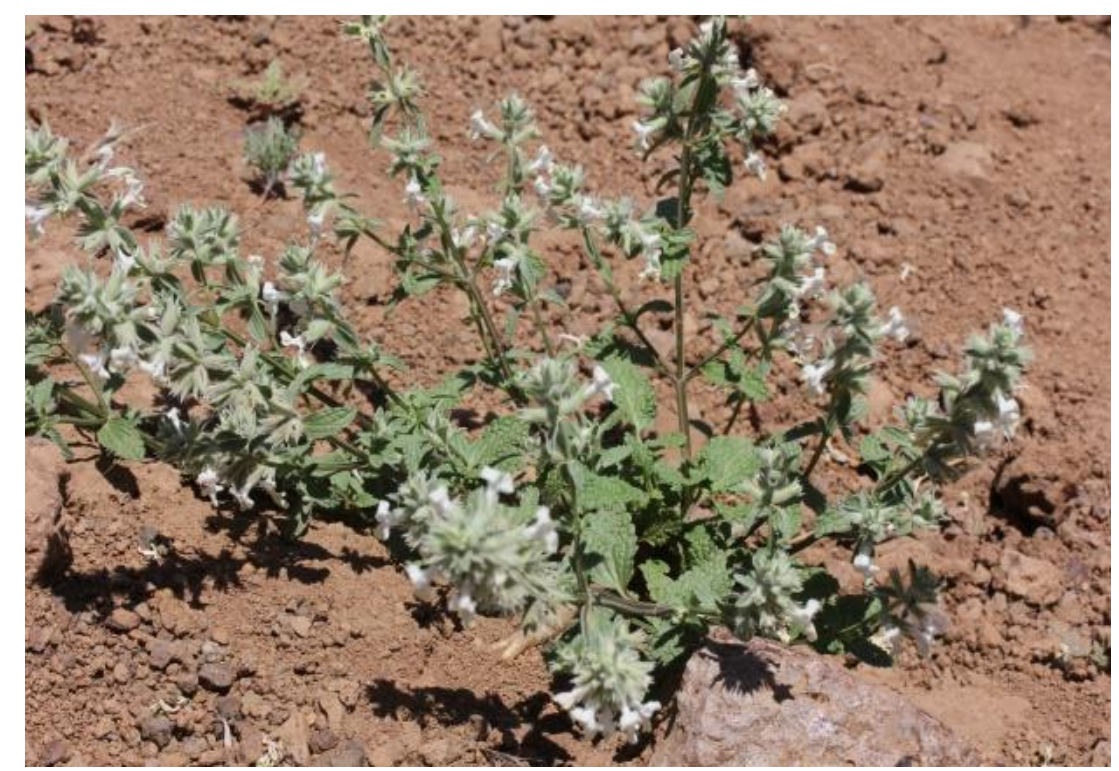

Şekil 5. Stachys annua subsp. annua var. lycaonica Bhattacharjee/hac1osmanotu

\section{Stachys thirkei K. Koch. /kestere}

Çirişli-Aşağıköy arası yol kenarı, step,1650 m, 01.07.2020, LY18864; Ortaköy kuzeyi, step, 15201560m, 15.07.2020, LY18939.

29. THYMUS L. /KEKİK

52. Thymus praecox Opiz. subsp. grossheimii (Ronniger) Jalas /yayla kekiği

Üçyaka-Balpınarı köyleri arası, 2. km, orman açıkları, 1650-1700 m, 23.06.2019, LY16910a; Yelesen köyü batısı, güneye bakan step yamaçlar, 2350 m, 28.06.2019, LY17066; Ortaköy-Şaban arası yayla yolu, 1. km, step yamaçlar, 1604 m, 31.07.2019, LY17781.

Çizelge 1. Çapakçur Vadisi'nde bulunan endemik bitkiler ve risk kategorileri

\begin{tabular}{ll}
\hline 1. Centaurea aggregata subsp. albida & Tehlike kategorisi \\
\hline 2. Ptilostilon afer subsp. eburneus & -- \\
3. Taraxacum davisii & LC(en az endişe verici) \\
4. Taraxacum revertens & EN(tehlikede) \\
5. Onobrychis stenostachya subsp. krausei & LC(en az endişe verici) \\
6. Trifolium roussaeanum & EN(tehlikede) \\
7. Scutellaria brevibracteata subsp. brevibracteata & VU(zarar görebilir) \\
8. Scutellaria orientalis subsp. haussknechtii & LC(en az endişe verici) \\
9. Scutellaria orientalis subsp. macrostegia & LC(en az endişe verici) \\
\hline
\end{tabular}

Çapakçur vadisinden Asteraceae, Fabaceae, Lamiaceae familyalarına ait 52 bitkinin B8 karesi için yeni yayılışları verilmiştir. Taksonlardan 9 tanesi (Centaurea aggregata Fisch. \& C.A.Mey. ex DC. subsp. albida (K.Koch) Bornm. /akküme, Ptilostilon afer ((Jacq.)Greuter subsp. eburneus Greuter, /has bozlanotu, Taraxacum davisii Soest /erek hindibas1, Taraxacum revertens G.Hagl. /caşir, Onobrychis stenostachya Freyn subsp. krausei (Sirj.) Hedge/dar korunga, Trifolium roussaeanum Boiss. /has yonca, Scutellaria brevibracteata Stapf subsp.brevibracteata /yağlı kaside, Scutellaria orientalis L.subsp. haussknechtii (Boiss.) J.R.Edm. /saçakl1 kaside, Scutellaria orientalis L. subsp. macrostegia (Hausskn. ex Bornem.) J.R.Edm. /takkeli kaside) endemiktir. Endemik taksonların tehlike kategorileri şu şekildedir: 2'si EN (tehlikede), 1'i VU (zarar görebilir), 4'ü LC (en az endişe verici), 2 'sinin tehlike kategorisi belirlenememiştir (Çizelge 1.). 
Alanda tespit edilen bitkilerin fitocoğrafik bölgelere göre dağılımı ise şu şekildedir; 19 takson İranTuran, 5 takson Avrupa-Sibirya, 4 takson Akdeniz fitocoğrafik bölge elementidir. 24 taksonun ise fitocoğrafik bölgesi bilinmeyen veya geniş yayılışlıdır.

\section{SONUÇ}

Çalışma sonucunda 30 takson Asteracea, 9 takson Fabaceae, 13 takson Lamiaceae üyesi toplam 52 taksonun yeni yayılış alanlarını belirlenmiş olup hem yazılmakta olan Resimli Türkiye Florasına hem de yapılan veya yapılacak olan monograf, revizyon ve flora çalışmalarına katkıda bulunulmuştur.

\section{TEŞEKKÜR}

Bu çalışma Cumhurbaşkanlığ Strateji ve Bütçe Başkanlığg tarafından finanse edilen ve Yüksek Öğretim Kurumu tarafından koordine edilen Bölgesel Kalkınma Odaklı Misyon Farklılaşması ve İhtisaslaşması Programı kapsamında Bingöl Üniversitesi Bilimsel Araştırma Projeleri Koordinasyon Birimi tarafindan (Proje No: 2017K124000-BÜBAP-PİKOM- Bitki.2018.007) desteklenmiştir.

\section{Çıkar Çatışması}

Makale yazarları aralarında herhangi bir çıkar çatışması olmadığını beyan ederler.

\section{Yazar Katkısı}

Yazarlar makaleye eşit oranda katkı sağlamış olduklarını beyan eder.

\section{KAYNAKLAR}

Behçet L, İlçim A, 2015. Paracaryum bingoelianum (Boraginaceae), a new species from Turkey. Turkish Journal of Botany, 39 (2): 334-340.

Behçet L, Yapar Y, 2020a. Türkiye'den Bazı Kareler İçin Yeni Floristik Kayıtlar. Bitlis Eren Üniversitesi Fen Bilimleri Dergisi, 9 (4): 1482-1495.

Behçet L, Yapar Y, 2020b. Lactuca anatolica (Asteraceae: Lactucinae), a new species from eastern Anatolia (Turkey). Phytotaxa, 455(4): 287-294.

Behçet L, Yapar Y, Sinan A, 2014. Contribution to the flora of Turkey from B8 square (Bingöl, Elazı $\breve{g} /$ Turkey). Biological Diversity and Conservation, 7 (3): 87-97.

Cheek M, Lughadha EN, Kirk P, Lindon H, Carretero J, Looney B, Douglas B, Haelewaters D, Gaya E, Llewellyn T, Ainsworth AM, Gafforov Y, Hyde K, Crous P, Hughes M, Walker BE, Campostrini R, Khoon F, Wong M, Niskanen T, 2020. New scientific discoveries: Plants and fungi. Plants, People, Planet, 2 (5): 371-388.

Davis PH, 1970. Flora of Turkey and the East Aegean Islands. Vol. 3. Edinburgh Univ. Press, Edinburgh, U.K.

Davis PH, 1975. Flora of Turkey and the East Aegean Islands. Vol. 5. Edinburgh Univ. Press, Edinburgh, U.K.

Davis PH, 1982. Flora of Turkey and the East Aegean Islands. Vol. 7. Edinburgh Univ. Press, Edinburgh, U.K.

Davis PH., Mill RR, Tan K, (Eds.) 1988. Flora of Turkey and the East Aegean Islands, Vol. 10, Edinburgh Univ. Press, Edinburgh, U.K.

Doğan M, Behçet L, Sinan A, 2015, Pseudophleum anatolicum, a New Endemic Species of Pseudophleum (Poaceae) from East Anatolia. Turkey. Systematic Botany, 40 (2): 454-460.

Duran A, Behçet L, Öztürk M, 2015. Diplotaenia bingolensis (Apiaceae), new species from east Anatolia, Turkey. Plant Syst Evol, 301: 467-478.

Ekim T, Koyuncu M, Vural M, Duman H, Aytaç Z, Adıgüzel N, 2000. Türkiye bitkileri kırmızı kitabı. Türkiye Tabiatııı Koruma Derneği ve Yüzüncü Y1l Üniv., Ankara.

Erik S, Tarıkkahya B, 2004. Türkiye florası üzerine. Kebkeç, 17: 139-163.

Güner A, Aslan S, Ekim T, Vural M, Babaç MT, 2012. Türkiye bitkileri listesi (Damarlı bitkiler). Nezahat Gökyiğit Botanik Bahçesi ve Flora Araştırmaları Derneği Yayını, İstanbul.

Güner A, Özhatay N, Ekim T, Başer KHC, 2000. Flora of Turkey and the East Aegean Islands. Vol.11,Edinburgh Univ. Press, Edinburgh, U.K. 
Haston E, Richardson JE, Stevens PF, Chase MW, Harris DJ, 2009. The Linear Angiosperm Phylogeny Group (LAPG) III: a linear sequence of the families in APG III. Botanical Journal of Linnean Society, 161: 128-131.

İlçim A, Behçet L, 2016. Astragalus topalanense (Fabaceae), a new species from Turkey. Turkish Journal of Botany, 40 (1): 74-80.

Kaval I, Behçet L, Çakılcığlu U, 2014. Ethnobotanical study on medicinal plants in Geçitli and its surrounding (HakkariTurkey). Journal of Ethnopharmacology, 155: 171-184.

Kawarty A, Behçet L, Çakılcıoğlu U, 2020. An ethnobotanical survey of medicinal plants in Ballakayati Erbil, North Iraq. Turkish Journal of Botany, 44 (3): 345-357.

Kılıç Ö, Yıldırımlı Ş, 2014. Dikme (kür) yaylası (Bingöl merkez) ve çevresinin fulorası. Ot Sistematik Botanik Dergisi, 21 (1): 69-126.

Kılıç Ö, Yıldırımlı Ş, Kıranşan K, 2017. Yüzenadalar (Bingöl-Solhan) çevresinin fulorası. Ot Sistematik Botanik Dergisi, 24 (2): 131-172.

Sinan A, Behçet L, 2014. The flora of Altıkardeş montain and its surroundings (Genç, Bingöl/ Turkey). Biological Diversity and Conservation, 7 (3): 97-116.

Yapar Y, Behçet L 2018. Hiro Yaylası Adakl1-Bingöl/Türkiye ve çevresinin florası. Biyolojik Çeşitlilik ve Koruma, 11 (3): 126-140.

Yıldırımlı Ş, 1999. The chorology of the Turkish species of Asteraceae family. Ot Sistematik Botanik Dergisi, 6 (2): $75-123$.

Yıldırımlı Ş, 2005. The chorology of the Turkish species of Fabaceae family. Ot Sistematik Botanik Dergisi, 12 (1): 117-170.

Yıldırımlı Ş, 2008. The chorology of the Turkish species of Lamiaceae family. Ot Sistematik Botanik Dergisi, 14 (1): 151-198. 